\title{
A Tale of Two Metrics: The EPA Risk Quotient Approach versus the Delay in Population Growth Index for Determination of Pesticide Risk to Aquatic Species
}

\author{
John D. Stark ( $\nabla$ starkj@wsu.edu ) \\ WSU Puyallup Research and Extension Center \\ John E. Banks \\ California State University Monterey Bay
}

\section{Research Article}

Keywords: Ecological risk assessment, pesticides, Daphnia, EPA, Risk Quotient, Delay in Population Growth Index

Posted Date: May 12th, 2021

DOl: https://doi.org/10.21203/rs.3.rs-481150/v1

License: (c) (1) This work is licensed under a Creative Commons Attribution 4.0 International License. Read Full License

Version of Record: A version of this preprint was published at Ecotoxicology on August 11th, 2021. See the published version at https://doi.org/10.1007/s10646-021-02462-x. 


\section{Abstract}

The risk that two closely related insecticides, spinetoram and spinosad, posed to three Cladoceran species, Ceriodaphnia dubia, Daphnia pulex, and D. magna was determined using two approaches, the USEPA Risk Quotient method and the Delay in Population Growth Index (DPGI). Results of the RQ method showed that spinetoram posed a risk to all three species, but spinosad posed a risk only to $C$. dubia. The DPGI analysis showed that exposure to spinetoram resulted in populations of all three species being delayed $\geq 3$ generation times. Exposure to the $\mathrm{LC}_{50}$ and the lower $95 \% \mathrm{CL}$ resulted in delayed populations while exposure to the upper $95 \% \mathrm{CL}$ concentration of spinetoram resulted in no recovery of any of the three species over the course of the modeling exercise (88 d). Exposure to the lower and upper $95 \% \mathrm{Cl}$ and the $L C_{50}$ of spinosad resulted in $C$. dubia populations being delayed $\geq 3$ generations. $D$. pulex populations were not negatively affected after exposure to spinosad. D. magna populations were delayed $\geq 3$ generations, but only after exposure to the upper $95 \% \mathrm{Cl}$ of spinosad. These results illustrate that although the EPA risk quotient method indicated that spinetoram posed a risk to all three species and that spinosad only posed a risk to $C$. dubia, the DPGI showed that $D$. magna would be negatively affected by spinosad and none of the three species would recover after exposure to the upper $95 \% \mathrm{CL}$ of spinetoram. Because the DPGI uses the $95 \% \mathrm{Cl}$ as well as the $\mathrm{LC}_{50}$ in its calculation and produces a measure of population growth and recovery or lack thereof, it provides more detailed information in terms of the potential risk of pesticides to populations than the RQ method.

\section{Introduction}

A central concern in risk assessment is accurately characterizing the effects of toxicants on different organisms - and using this characterization to effectively and accurately predict how different species will react to different toxicants. Historically, risk assessment has relied heavily on static point-estimates of toxicity such as $L_{50}$ or $L_{50}$. In recent decades, a large number of studies have highlighted the importance of moving beyond this static-metric approach to consider population-endpoints (Sibly 1999; Banks and Stark 1998; Forbes and Calow 2002; Stark and Banks 2001, 2003; Stark et al. 2004; Billoir et al. 2008; Banks et al. 2008; Dalkvist et al. 2009; Banks and Stark 2009; Grimm et al. 2009; Forbes et al. 2011; Van den Brink 2013; Stark and Banks 2016). Simply speaking, point estimates such as the $\mathrm{LC}_{50}$ cannot capture population-level effects that consider differences in demographic vital rates. Differences exist among species in various demographic vital rates such that some species reach sexual maturity quickly, have many broods and offspring, and have a short life span (e.g. rats) and other species take a long time to reach sexual maturity, have long life spans, and few offspring (e.g. elephants). These differences in vital rates make some species less susceptible to stress than others (Stark et al 2004). Several studies have now shown that differences in vital rates among even closely related species can result in different population outcomes after exposure to toxicants (Stark et al. 2004; Banks et al. 2010, 2011, 2014, 2017). 
The United States Environmental Protection Agency (USEPA) uses a tiered ecological risk assessment approach to estimate potential risk of pesticides to various species by comparing species susceptibility to an expected environmental concentration (EEC) (USEPA 2004). A ratio called a risk quotient (RQ) is compared to a level of concern (LOC) for pesticides. If the ratio exceeds the LOC, then the pesticide poses an environmental risk. The EPA approach uses a point estimate for toxicity, the $\mathrm{LC}_{50}$.

In contrast, Wennergren and Stark (2000) developed an approach to pesticide risk assessment called the Delay in Population Growth Index (DPGI) that takes into account population-level effects by evaluating the recovery of a population after pesticide exposure. The DPGI involves the development of matrix population models for control populations and populations exposed to pesticides. These pesticideexposed populations are compared to the control, and the time to recovery is the endpoint of interest. Stark et al. (2015) used the DPGI to evaluate the effects of pesticides on pest and beneficial species.

In this study, we directly compare the effectiveness of two risk assessment approaches using lab-derived data for several closely-related important environmental indicator species subjected to two different pesticides. In particular, we developed risk assessments for three Cladoceran species, Ceriodaphnia dubia, Daphnia pulex, and D. magna exposed to the insecticides spinosad and spinetoram, using the EPA and DPGI methods. We then compared the results of the EPA Risk Quotient method and the DPGI in order to quantify differences in these two methods in terms of the risk of pesticides to aquatic organisms exposed to pesticides.

\section{Materials And Methods}

\section{Insecticides evaluated}

Spinosad (Dow AgroSciences LLC, Indianapolis, IN) is a natural insecticide derived from the fermentation of a strain of Saccharo-polyspora spinosa. A mixture of spinosyns A and D, which make up the active ingredients of spinosad, are extracted from the fermentation broth. Spinetoram is a mixture of chemically modified spinosyns $\mathrm{J}$ and $\mathrm{L}$. Spinosyns $\mathrm{J}$ and $\mathrm{L}$ are obtained after fermentation of a mutant strain of Saccharopolyspora spinosa that produces primarily spinosyns $\mathrm{J}$ and $\mathrm{L}$, instead of spinosyns $\mathrm{A}$ and $\mathrm{D}$. Spinosyns $J$ and $L$ then undergo two chemical synthesis steps to produce the final product, spinetoram. Both spinosad and spinetoram are neurotoxic and the mode of action is to disrupt the nicotinic and GABA-gated chloride channels (Galm and Sparks 2016).

The USEPA considers spinosad and spinetoram to be "toxicologically equivalent" and that the major risk they pose is to freshwater invertebrates, but only after chronic exposure (USEPA 2009).

\section{Acute mortality data used in population models}

Acute mortality data for $C$. dubia, D. pulex and D. magna exposed to Spinosad and spinetoram have been previously published (Deardorff and Stark 2009; Stark and Banks 2019). The $\mathrm{LC}_{50}$ and their respective 95\% CLs for each species and pesticide were used to parameterize matrix population models (Table 1). 
Expected environmental concentrations (EEC) of spinetoram and spinosad in freshwater systems have been developed. The EECs for spinetoram (EPA 2007) and spinosad (Federal Register 2005) are 14.4 and $2.3 \mu \mathrm{g} / \mathrm{l}$, respectively.

\section{EPA RQ development}

RQs for Spinosad and the three Daphniid species have been previously published (Deardorff and Stark 2009). RQs for spinetoram and the three Daphniid species were developed by dividing the EEC/LC ${ }_{50}$ for each insecticide and species. RQs developed for each species and insecticide were compared to a level of concern of 0.5 . RQs that exceeded 0.5 indicated that the insecticide posed a risk to that species.

\section{Population model construction and development of the DPGI}

We define the delay in population growth index as the number of days it takes for a pesticide-exposed population to grow from 100 to 1,000 individuals minus the number of days it takes the control population to grow from 100 to 1,000 individuals (Wennergren and Stark 2000; Stark et al. 2004; Stark et al. 2015). Percent mortalities corresponding to exposure to the EECs for spinosad ( $2.3 \mu \mathrm{g} / \mathrm{l})$ and spinetoram $(14.4 \mu \mathrm{g} / \mathrm{l})$ were calculated by reading mortality values from the concentration response curves for the daphniid species, Ceriodaphnia dubia, Daphnia pulex and D. magna (Figs 1 \& 2). Percent mortalities were read from the mean, lower, and upper $95 \% \mathrm{CL}$ curves (Table 2).

The predicted mortality estimates read from the LC curve, upper, and lower 95\% CL curves (Table 2) were incorporated into matrix population models to develop the Delay in Population Growth Index (DPGI) (Wennergren and Stark 2000; Stark et al 2004; Stark et al. 2015). Thus, three models were developed for each mortality estimate, one model for each control population for each of the three species for each insecticide (24 models in total).

Stochastic matrix population models were developed using RAMAS Metapop ${ }^{\circledR}$ software (Akçakaya 2005). Models were developed for $C$. dubia, D. magna, and D. pulex based on the approach outlined in Stark et al. (2015). The models were stage structured and consisted of vital rates for a neonate, juvenile 1 , juvenile 2, and adult stage (Table 3). Populations were started as 100 individuals in the stable age distribution for each species. Ceiling density dependence was incorporated into each matrix model with 1,000 individuals as the final population size. Each model was run 1,000 times by resampling using a Monte Carlo method in RAMAS. The time step of each matrix multiplication was four days, which corresponded to the approximate generation time for each species (Banks et al. 2019). The model was run for 22-time steps which corresponded to 88 days, which was supposed to approximate a summer season in a temperate zone. Model runs resulted in population trajectories for each species exposed to the two insecticides over an 88d period.

The DPGI was also converted from delays in recovery time (in terms of days) to the number of generations (based on a 4-d generation time) that could have been produced during the delay time 
interval. A population delay was considered to cause significant damage if the pesticide-exposed population was delayed $\geq$ three generations over the $88 \mathrm{~d}$ of the study timeframe.

\section{Results}

\section{EPA RQ}

Results of the EPA RQ method showed that spinetoram posed a risk to all three species while spinosad only posed a risk to $C$. dubia (Table 4).

\section{Spinetoram DPGI}

Results of the DIPG modeling study showed that population growth of all three species was delayed after exposure to spinetoram compared to the control after exposure to mortality levels obtained from the lower and upper $95 \% \mathrm{CL}$ and the $\mathrm{LC}_{50}$ curves (Figs. 3-5, Table 5). Population recovery occurred after exposure to mortality levels obtained from the lower $95 \% \mathrm{CL}$ and $\mathrm{LC}_{50}$ curves. However, none of the three species recovered after being subjected to mortality obtained from the spinetoram upper $95 \%$ over the time frame of this study (Fig. 3-5, Table 5).

Population delays were also examined in terms of the number of generations that could have been completed during the delay time interval. All three species were delayed for 3 or more generations after exposure to mortality derived from the lower $95 \% \mathrm{Cl}$ and LC curve at the EEC (Table 5).

D. pulex was the most negatively affected species in terms of days of delay and number of generations that could have been completed followed by $D$. magna and $C$. dubia after exposure to mortality from the LC curve (Table 5). In contrast, according to the RQ method, D. magna had the highest quotient indicating it was most at risk, followed by D. pulex and then C. dubia (Table 4).

\section{Spinosad DPGI}

Results of the DIPG modeling study showed that populations of $C$. dubia and D. magna were delayed after exposure to spinosad, but $D$. pulex populations were unaffected after exposure to the Spinosad EEC (Figs. 6-8, Table 5).

Population delays in terms of the number of generations that could have been completed during the delay time interval showed that $C$. dubia populations were delayed for 3 or more generations after exposure to mortality derived from the lower and upper $95 \% \mathrm{Cl}$ and the LC curve at the EEC (Table 5). $D$. magna populations were delayed for $>3$ generations after exposure only to mortality from the upper $95 \%$ $\mathrm{Cl}$ (Table 5).

The RQ method indicated that Spinosad posed a risk only to $C$. dubia, but the RQ for $D$. magna (0.48) was close to the 0.5 level of concern (Table 4). 


\section{Discussion}

In this study, both the EPA RQ method and the DPGI yielded similar results for the insecticide spinetoram and three daphniid species. However, the DPGI provided more information with regard to population-level impacts. The RQ method for Spinosad showed that this insecticide only posed a risk to $C$. dubia. However, the RQ for D. magna was borderline (0.48) and could be rounded to 0.5 indicating that Spinosad at the EEC would also pose a risk to D. magna. The DPGI for Spinosad provided more detailed information about population-level effects, highlighting that $D$. magna populations would only be negatively affected (>3 generation delay) after mortality levels obtained from the upper $95 \% \mathrm{CL}$.

Risk assessment methodologies are often refined in order to optimize tradeoffs between cost and accuracy. For instance, in human health risk assessment, toxicity has traditionally been measured by applying uncertainty factors to standard point-estimates of risk to calculate reference doses or concentrations (Price et al. 1999). Recently the World Health Organization has been exploring moving away from using these point estimates, instead using probability distributions for reference doses/concentrations, citing the need for a more holistic understanding of the risk to human health posed by environmental toxicants (Bhat et al. 2017). In risk assessment for animal populations, pointestimates such as $L C / L D_{50}$ measures remain the standard - they are simple to develop and easy to generate across a multitude of species, thereby rendering them ideal for large-scale comparisons and policy guidance. In contrast, population endpoints require more extensive time and resources to develop than static measures, requiring partial life tables at a minimum (Stark and Banks 2016). However, these latter metrics provide more insight into the nuances of species' responses to toxicants. In some cases, population level analyses and population recovery can lead to major insights into the nature of toxicant risks, revealing risks not detected by static metrics (Stark and Banks 2003, Stark et al. 2004, Barnthouse 2009, Knillmann et al. 2012, Baveco et al. 2014).

In the current study, we illustrated that the major advantage for using the RQ method is that it requires less work to develop than the DPGI. In contrast, however, using the DPGI allows for the incorporation of the $\mathrm{LC}_{50} 95 \%$ CLs as well as providing a population-level measure of effects. We anticipate that differences in output/accuracy of these two methods will vary with species and toxicants. We evaluated only two insecticides and three species in this study, but to gain a better understanding of the value of the $\mathrm{RQ}$ and DPGI methods, additional studies should be conducted in the future.

\section{Declarations}

\section{Acknowledgments}

We thank Oriki and Grace Jack for help with carrying out the toxicity studies and collecting data.

\section{Funding}


Funding for this project was provided by Washington State University and California State University as partial salary and benefits for the authors

\section{Conflicts of interest/Competing interests}

Not applicable

\section{Availability of data and material}

All data and models are available upon request to the authors

\section{Code availability}

Not applicable

\section{Authors' contributions}

Both authors contributed equally to the development of this study, gathering of data, statistical analysis of the data and writing of the manuscript.

\section{Ethics approval}

Not applicable

\section{Consent to participate}

Not applicable

\section{Consent for publication}

Not applicable

\section{References}

Akçakaya HR. 2005. RAMAS Metapop: Viability Analysis for Stage-Structured Metapopulations (version 5.0). Applied Biomathematics, Setauket, New York.

Banks J, Stark JD (1998) What is ecotoxicology? An ad-hoc grab bag or an interdisciplinary science? Integr Biol 5: 195-204.

Banks JE, Stark JD (2009) Ecotoxicology: life history data and population models, In Santos, E.B. (ed.) Ecotoxicology Research Developments, Nova Science Publishers, Inc

Banks JE, Dick LK, Banks HT, Stark JD (2008) Time-varying disturbance parameters in ecology: an alternative to matrix models. Ecol Model 210:155-160. 
Banks JE, Ackleh A, Stark JD (2010) The use of surrogate species in risk assessment: using life history data to safeguard against false negatives. Risk Anal 30:175-182.

Banks JE, Stark JD, Vargas RI, Ackleh A (2011) Parasitoids and ecological risk assessment: Can toxicity data developed for one species be used to protect an entire guild? Biol Control 59: 336-339.

Banks JE, Stark JD, Vargas RI, Ackleh AS (2014) Deconstructing the surrogate species concept: a life history approach to the protection of ecosystem services. Ecol Appl 24:770-778.

Banks J, Vargas R, Ackleh A, Stark JD (2017) Sublethal effects in pest management: a surrogate species perspective on fruit fly control. Insects 8, 78; doi:10.3390/insects8030078.

Banks J, Ackleh A, Veprauskas A, Stark JD (2019) The trouble with surrogates in risk assessment: a daphniid case study. Ecotoxicology 28:62-68.

Barnthouse LW. 2009 Quantifying population recovery rates for ecological risk assessment Environ Toxicol Chem 23:500-508.

Bhat VS, Meek ME, Valcke M, English C, Boobis A, Brown R (2017) Evolution of chemical-specific adjustment factors (CSAF) based on recent international experience; increasing utility and facilitating regulatory acceptance, Crit Rev Toxicol 47(9): 733-753, DOI: 10.1080/10408444.2017.1303818

Billoir E, Pery ARR, Charles S (2008). Integrating the toxic and sublethal effects of toxic compounds into the population dynamics of Daphnia magna:Acombination of the DEBtox and matrix population models. Ecol Model 203:204-214.

Baveco JMH, Norman S, Roessink I, Galic N, Van den Brink PJ. (2014) Comparing population recovery after insecticide exposure for four aquatic invertebrate species using models of different complexity. Environ Toxicol Chem 33:1517-28.

Dalkvist T, Topping CJ, Forbes VE (2009) Population-level impacts of pesticide-induced chronic effects on individuals depend more on ecology than toxicology. Ecotox Environ Safe 72(6):1663-1672.

Deardorff A, Stark JD (2009) Acute toxicity and hazard Assessment of Spinosad and R-11 to three Cladoceran species and Coho salmon. Bull. Environ. Contam Toxicol 82: 549-553.

EPA (2007) Environmental Protection Agency 40 CFR Part 180 [EPA-HQ-OPP-2007-0876; FRL-81499] Spinetoram; Pesticide Tolerance (https://www.govinfo.gov/content/pkg/FR-2007-10-10/pdf/E719947.pdf)

Federal Register (2005) Spinosad; notice of filing a pesticide petition to establish a tolerance for a certain pesticide chemical in or on food. Volume 70, Number 138. [Notices] [pp 41730-41735] From the Federal Register Online via GPO Access [wais.access.gpo.gov] [DOCID:fr20jy05-67] 
Forbes VE, Calow P (2002) Population growth rate as a basis for ecological risk assessment of toxic chemicals. Phil Trans Biol Sci 357:1299-1306.

Forbes VE, Calow P, Grimm V, Hayashi T, Jager T, Palmpvist A, Pastorok R, Salvito D, Sibly

R, Spromberg J, Stark J, Stillman RA (2010) Integrating population modeling into ecological risk assessment. Integr Environ Assess Manage 6:191-193.

Forbes VE, Calow P, Grimm V, Hayashi TI, Jager T, Katholm A, Palmqvist A, Pastorok R, Salvito D, Sibly R, Spromberg J, Stark JD, Stillman RA (2011) Adding value to ecological risk assessment with population modelling. Human Ecol Risk Assess17: 287-299. Forbes et al. 2011

Galm U, Sparks TC (2016) Natural product derived insecticides: Discovery and development of spinetoram. J Ind Microbiol Biotechnol 43: 185-193.

Grimm V, Ashauer R, Forbes V, Hommen U, Preuss TG, Schmidt A, Van den Brink PJ, Wogram J, Thorbek P (2009) CREAM: A European project on mechanistic effect models for ecological risk assessment of chemicals. Environ Sci Pollut Res 16:614-617.

Knillmann S, Stampfli NC, Noskov YA et al. (2012) Interspecific competition delays recovery of Daphnia spp. populations from pesticide stress. Ecotoxicology 21:1039-1049.

Price PS, Keenan RE, Schwab B (1999) Defining the interindividual (intraspecies) uncertainty factor. Hum Ecol Risk Assess 5(5): 1023-1033 DOI: 10.1080/10807039991289310

Sibly RM (1999). Efficient experimental designs for studying stress and population density in animal populations. Ecol Appl 9: 496-503.

Stark JD, Banks JE (2001) "Selective Pesticides”: Are They Less Hazardous to the Environment? BioScience 51: 980-982.

Stark JD, Banks JE (2003) Population-level effects of pesticides and other toxicants on arthropods. Annu Rev Entomol 48: 505-19.

Stark JD, Banks JE, Vargas RI (2004) How risky is risk assessment? The Role that Life History Strategies Play in Susceptibility of Species to Stress. Proc Nat Acad Sci 101: 732-736.

Stark JD, Vargas, RI, Banks JE (2015) Incorporating variability in point estimates in risk assessment: bridging the gap between $\mathrm{LC}_{50}$ and population endpoints. Environ Toxicol Chem 34: 1683-1688.

Stark JD, Banks JE (2016) Developing demographic toxicity data: Optimizing effort for predicting population outcomes in ecotoxicology. PeerJ 4:e2067; DOI 10.7717/peerj.2067 
Stark JD, Banks JE (2019) Comparative toxicity of the semi-natural insecticide Spinetoram (Delegate ${ }^{\text {TM }}$ ) to three Cladoceran species. Biopestic Int 15:1-4.

USEPA (2004) Overview of the Ecological Risk Assessment Process in the Office of Pesticide Programs, U.S. Environmental Protection Agency: Endangered and Threatened Species Effects Determinations. https://www3.epa.gov/pesticides/endanger/consultation/ecorisk-overview.pdf

USEPA (2009) Office of Prevention, Pesticides and Toxic Substances (7505P) Spinetoram Pesticide Fact Sheet 2009.

Van den Brink PJ (2013) Assessing aquatic population and community-level risks of pesticides. Environ Toxicol Chem 32: 972-973. https://doi.org/10.1002/etc.2210

Wennergren U, Stark JD (2000) Modeling long-term effects of pesticides on populations: beyond just counting dead animals. Ecol Appl 10: 295-302.

\section{Tables}

Table 1. Acute mortality estimates of spinetoram and spinosad to three Daphniid species

\begin{tabular}{lll}
\hline & $\begin{array}{l}\text { Spinetoram (Delegate) })^{1} \\
\text { Species }\end{array}$ & $\begin{array}{l}\text { Spinosad (Success) } \\
\\
\end{array}$ \\
& $\begin{array}{l}\mathrm{LC}_{50}(95 \% \mathrm{CL}) \\
(\mu \mathrm{g} \mathrm{ai} / \mathrm{L} \text { water })\end{array}$ & $(\mu \mathrm{g} \mathrm{ai} / \mathrm{L}$ water $)$ \\
\hline C. dubia & $12.6(4.0-25.2)$ & $1.8(1.3-2.5)$ \\
D. pulex & $3.4(1.0-9.5)$ & $129(77-181)$ \\
D. magna & $10.5(2.5-36.8)$ & $4.8(1.9-10)$ \\
& & \\
\hline
\end{tabular}

1/Data from Stark and Banks 2019.

2/Data from Deardorff and Stark 2009.

Table 2. Predicted acute mortality for three Cladoceran species exposed to $14.4 \mu \mathrm{g} / \mathrm{l}$ spinetoram or 2.3 $\mu \mathrm{g} / \mathrm{l}$ spinosad derived from concentration-mortality curves. 
Spinetoram Spinosad
C. dubia
$52(40-64)^{1}$
$55(49-59)^{1}$
D. pulex
$61(52-70)$
$4(1-15)$
D. magna
$53(42-64)$
$40(28-52)$

$1 /$ first value is mortality derived from the lethal concentration curve. Values in parentheses are mortality derived from the lower and upper $95 \%$ CL curves (Figs. $1 \& 2$ ).

Table 3. Four stage vital rates for the three daphniid species calculated on a four-day timestep (from Banks et al. 2018).

\begin{tabular}{|lccccc|}
\hline & $\mathrm{S}_{1}$ & $\mathrm{~S}_{2}$ & $\mathrm{~S}_{3}$ & $\mathrm{~S}_{4}$ & $\mathrm{~S}_{5}$ \\
\hline C. dubia & 1 & 1 & 1 & 0.81 & 18.69 \\
\hline D. pulex & 1 & 1 & 1 & 0.71 & 25.13 \\
\hline D. magna & 1 & 1 & 1 & 0.80 & 17.53 \\
\hline
\end{tabular}

$S_{1}=$ survival in the neonate stage, $S_{2}=$ survival in the juvenile 1 stage, $S 3=$ survival in the juvenile 2 stage, $S 4$ survival in the adult stage, $f=$ fecundity

Table 4. Risk Quotients (RQ) for spinetoram and Spinosad and three Daphniid species.

\begin{tabular}{|lll|}
\hline Species & RQ for spinetoram & RQ for spinosad \\
& 1,2 \\
\hline C. dubia & 1.15 & 1.29 \\
\hline D. magna & 4.19 & 0.48 \\
\hline D. pulex & 1.37 & 0.02 \\
\hline
\end{tabular}

1/ Risk assessment values were calculated with the equation:

Risk $=\mathrm{EEC} / \mathrm{LC}_{50}$.

Values greater than 0.5 indicate that the chemical poses a risk to the tested species.

2/from Deardorff and Stark 2009. 
Table 5. Delay in population growth after exposure to the expected environmental concentration of spinetoram or spinosad.

\begin{tabular}{|c|c|c|c|}
\hline & \multicolumn{3}{|l|}{ Spinetoram } \\
\hline & Lower 95\% CL & $\mathrm{LC}_{50}$ & Upper 95\% CL \\
\hline \multicolumn{4}{|c|}{ Delay $(d)^{1}$ [generations] $^{2}$} \\
\hline C. dubia & $12[3]$ & $24[6]$ & No recovery ${ }^{3}$ \\
\hline D. pulex & $16[4]$ & $40[10]$ & No recovery \\
\hline \multirow[t]{3}{*}{ D. magna } & $12[3]$ & $28[7]$ & No recovery \\
\hline & Spinosad & & \\
\hline & Lower 95\% CL & $\mathrm{LC}_{50}$ & Upper 95\% CL \\
\hline C. dubia & $16[4]$ & $24[6]$ & $44[11]$ \\
\hline D. pulex & $0[0]$ & $0[0]$ & $0[0]$ \\
\hline D. magna & $4[1]$ & 8 [2] & $24[6]$ \\
\hline
\end{tabular}

1/ Number of days it takes for a pesticide-exposed population to grow from 100 to 1,000

individuals minus the number of days it takes the control population to grow from 100 to 1,000 individuals (Stark et al. 2004).

2/ number of generations (based on a 4-d generation time) that could have been produced during the delay time interval.

3/population does not recover (reach 1,000 individuals) over the length of the study

\section{Figures}




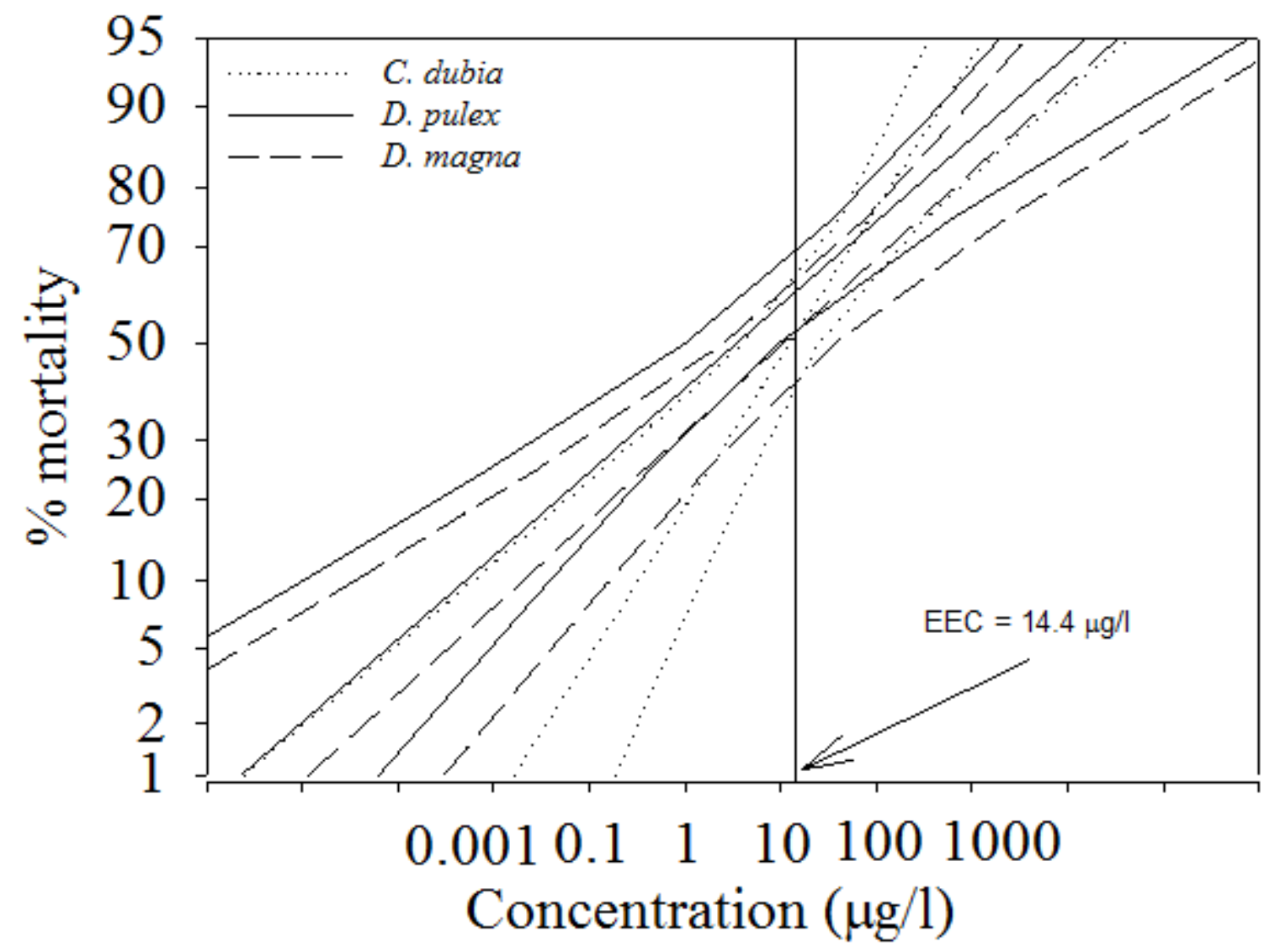

Figure 1

Acute concentration-response curves for three Cladoceran species exposed to Spinetoram 


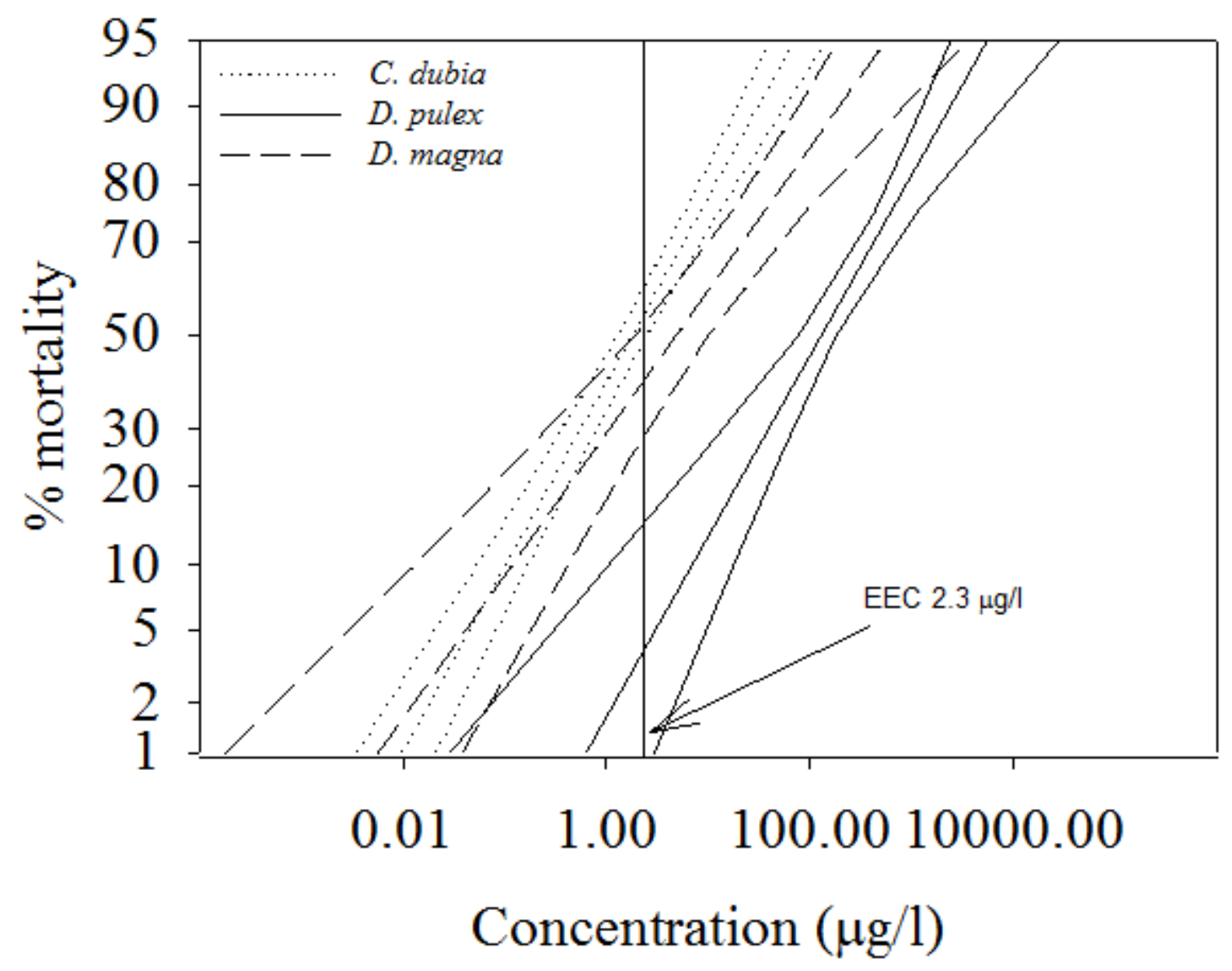

Figure 2

Acute concentration-response curves for three Cladoceran species exposed to Spinosad. 


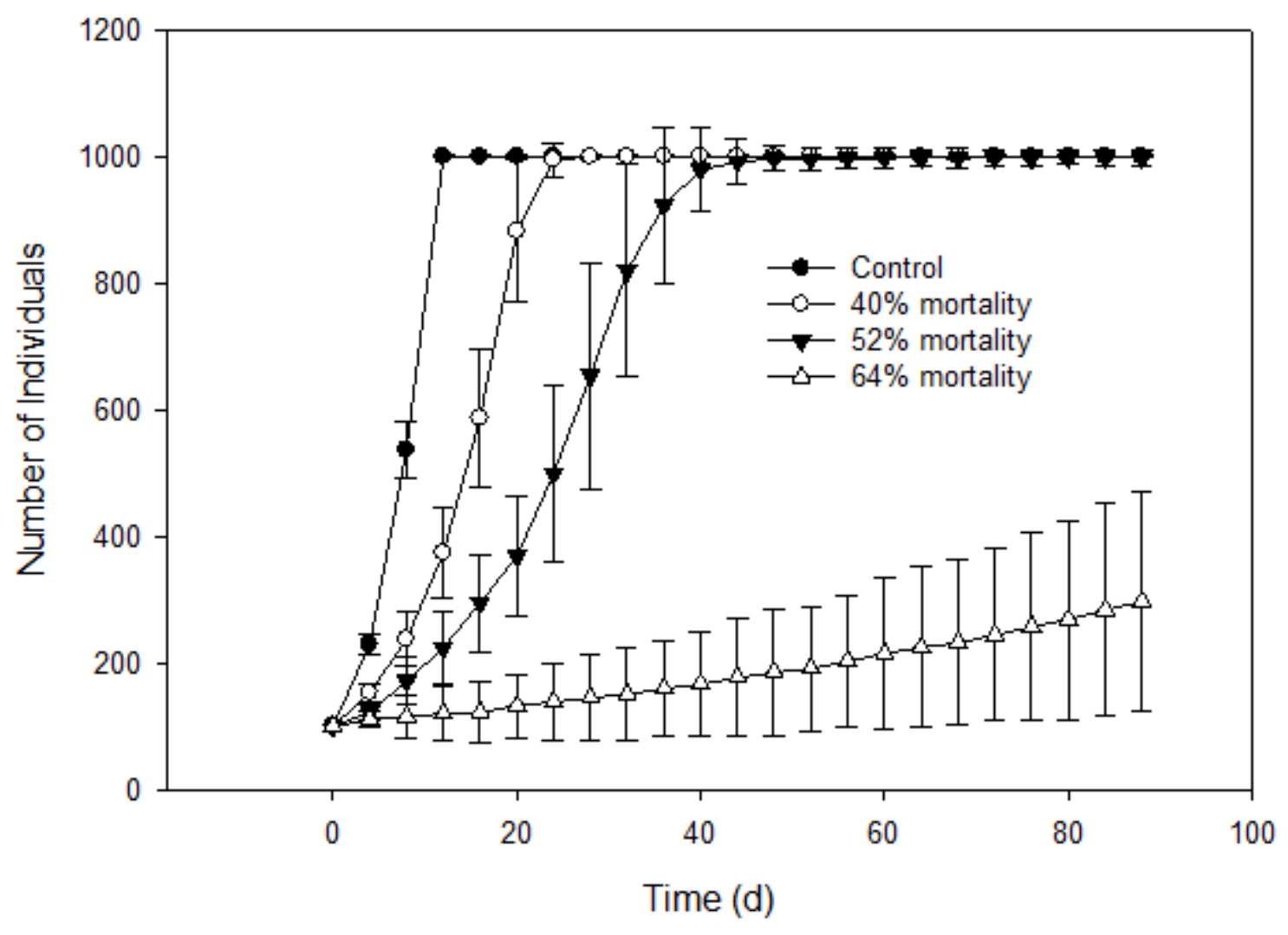

Figure 3

Population size of $\mathrm{C}$. dubia after imposing mortality values from the spinetoram LC curve, lower and upper $95 \%$ CL curves that correspond to exposure to the EEC. 


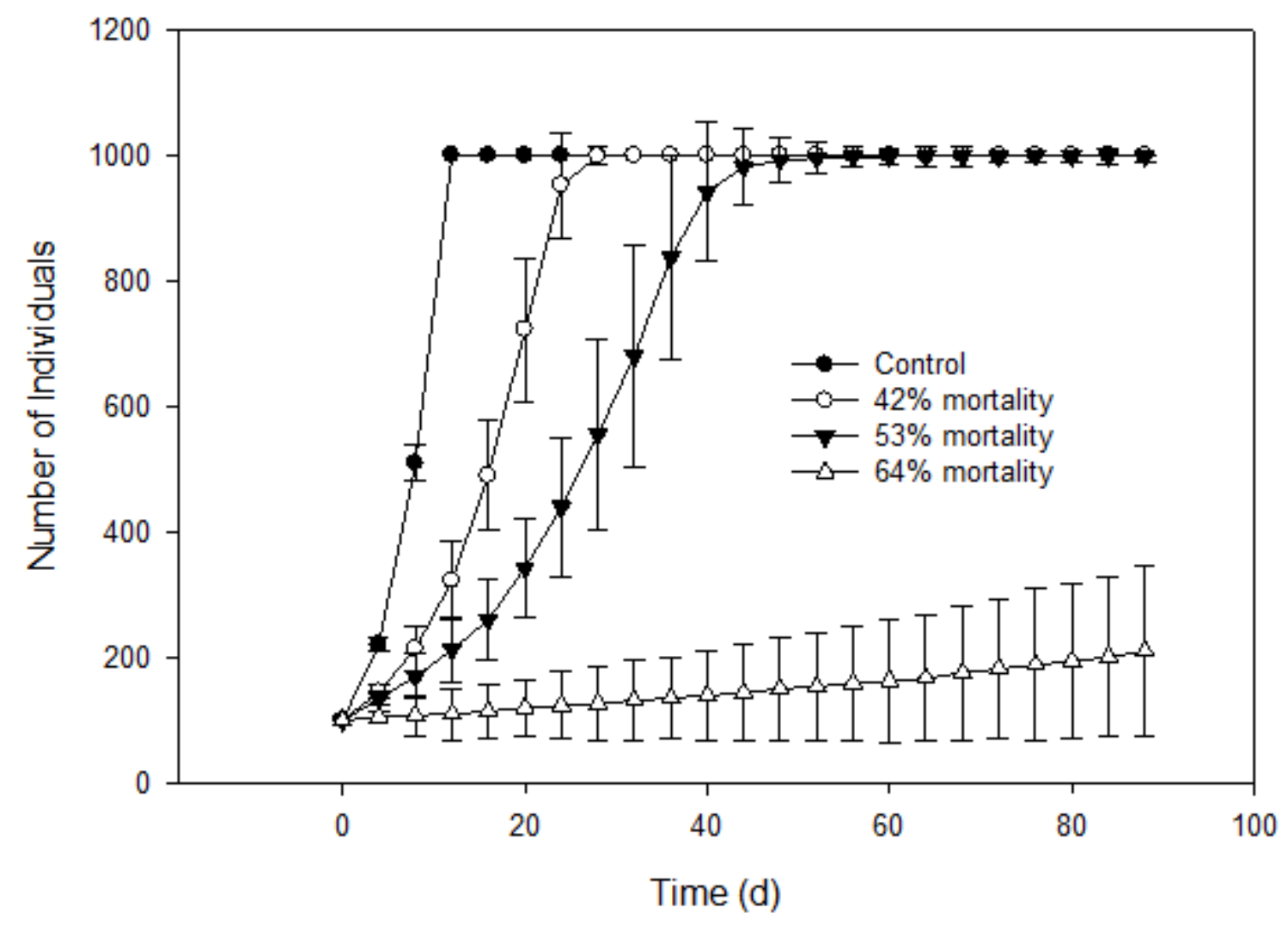

Figure 4

Population size of D. magna after imposing mortality values from the spinetoram LC curve and the lower and upper $95 \% \mathrm{CL}$ curves that correspond to exposure to the EEC. 


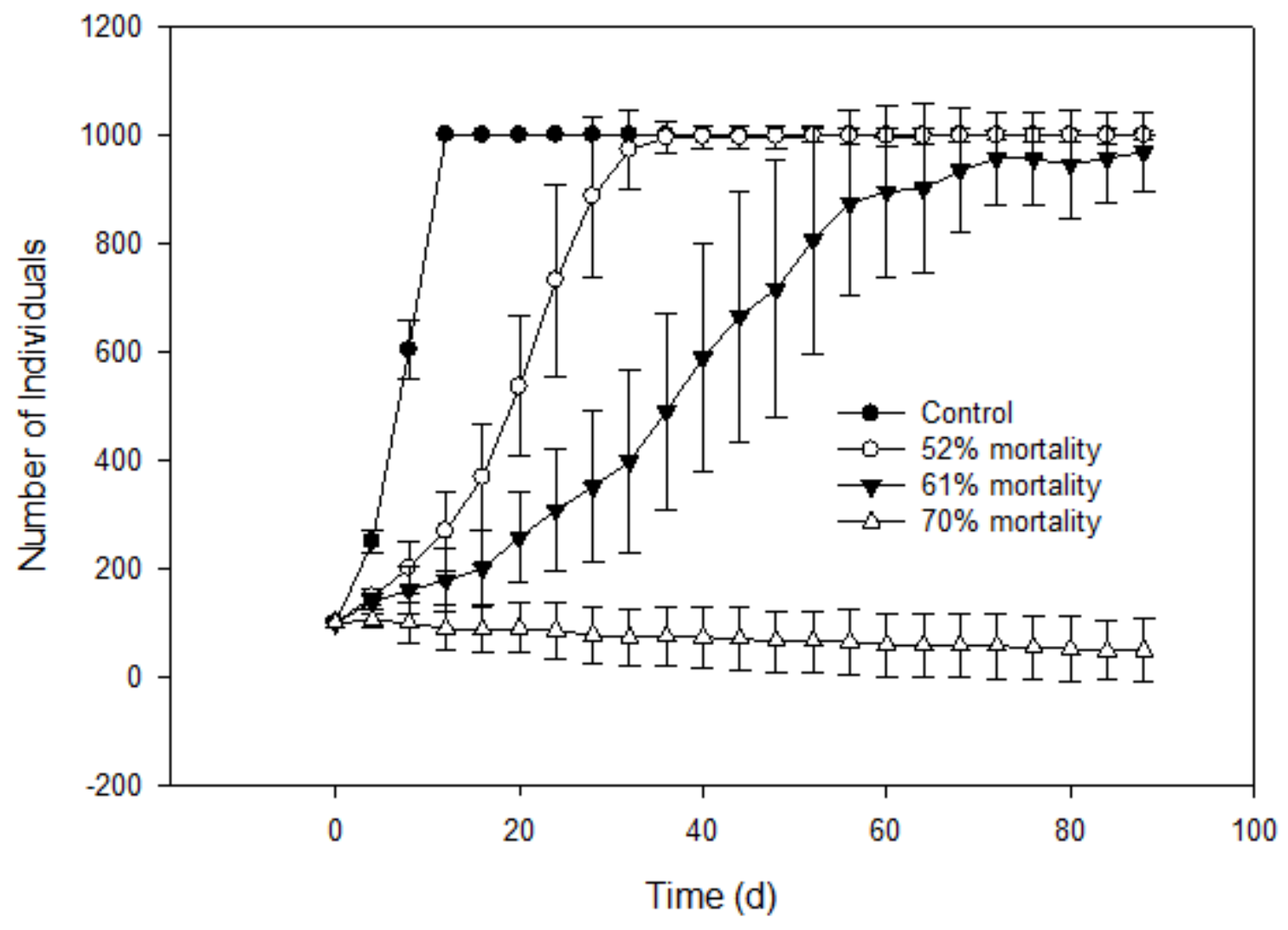

Figure 5

Population size of D. pulex after imposing mortality values from the spinetoram LC curve, lower and upper $95 \%$ CL curves that correspond to exposure to the EEC. 


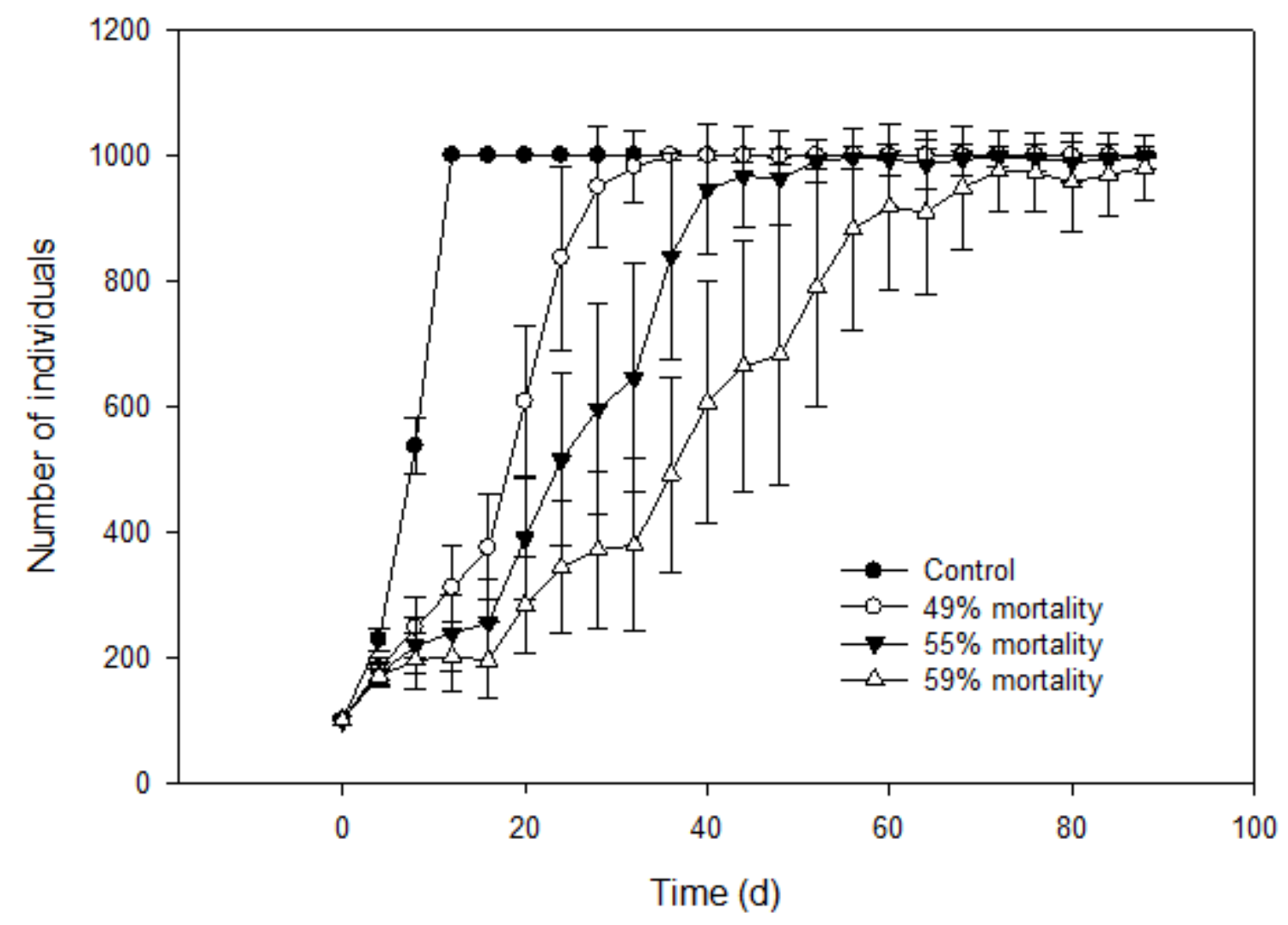

Figure 6

Population size of $\mathrm{C}$. dubia after imposing mortality values from the spinosad LC curve, lower and upper $95 \% \mathrm{CL}$ curves that correspond to exposure to the EEC. 


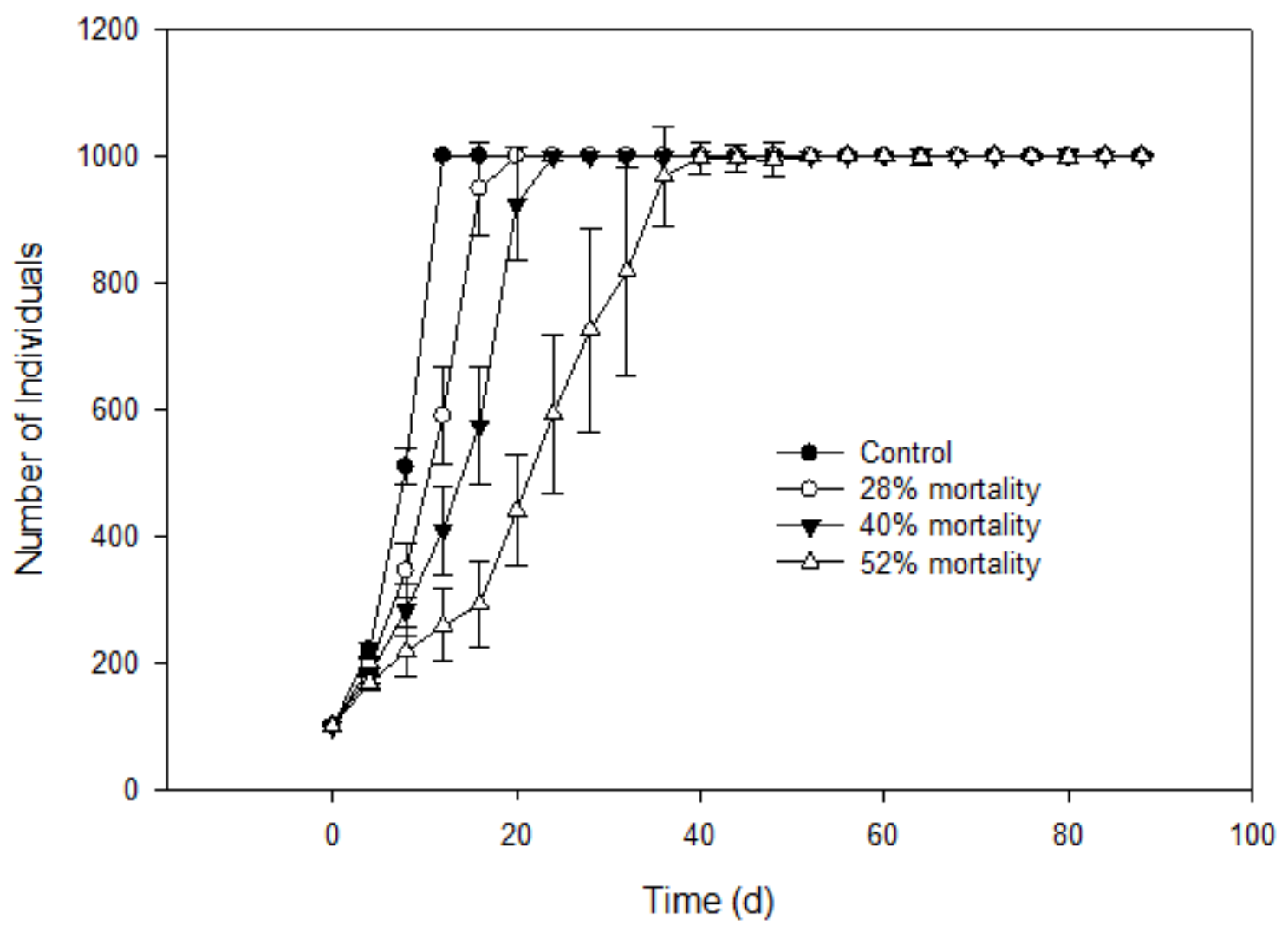

Figure 7

Population size of D. magna after imposing mortality values from the spinosad LC curve, lower and upper $95 \% \mathrm{CL}$ curves that correspond to exposure to the EEC. 


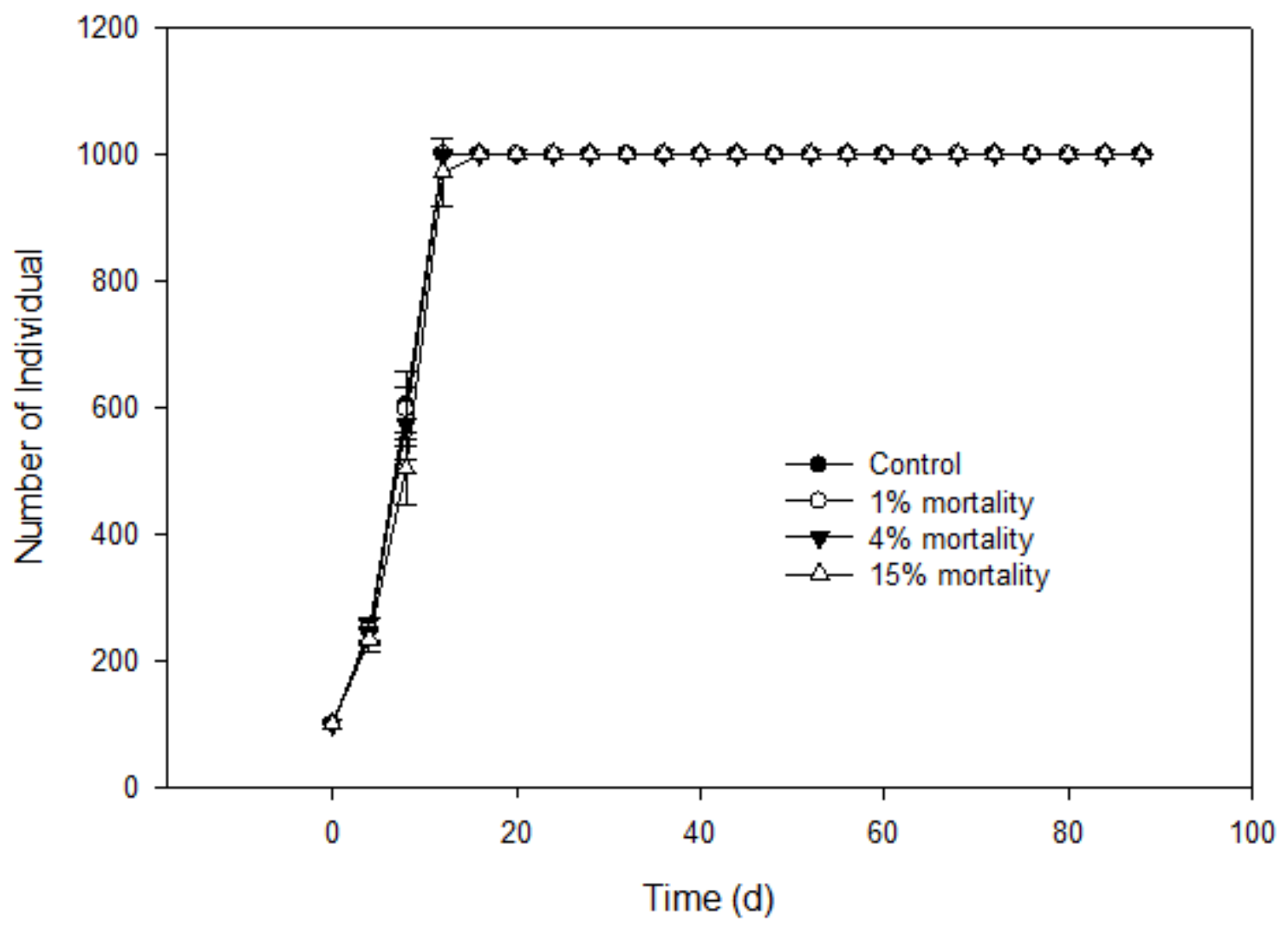

Figure 8

Population size of D. pulex after imposing mortality values from the spinosad LC curve, lower and upper $95 \% \mathrm{CL}$ curves that correspond to exposure to the EEC. 